\title{
Correlation of platelet count and platelet volume indices with coronary artery diseases
}

\author{
Gamit M. ${ }^{1}$, Rathod G. ${ }^{2 *}$ \\ DOI: https://doi.org/10.17511/jopm.2020.i04.07
}

1 Mital Gamit, Assistant Professor, Department of Pathology, GMERS Medical College, Vadnagar, Gujarat, India.

2* Gunvanti Rathod, Associate Professor, Department of Pathology, GMERS Medical College, Ahmedabad, Gujarat, India.

Introduction: Coronary artery disease is the most common non-communicable disease in the world. Platelet activation plays a central role in the transformation of atherosclerotic cardiovascular disease (CVD) into its potentially major adverse clinical events, such as ischemic stroke and myocardial infarction. Aim and objectives: The aim of this study was to study platelet parameters e.g. platelet count, mean platelet volume, platelet distribution width, and mean platelet concentrate in the spectrum of ischemic artery disease and to attempt a clinicopathological correlation. Materials and methods: This study was done in the hematological section of the pathology department at tertiary care hospital over a period from January 2016 to December 2018. The study population was divided into three groups healthy control, patients of myocardial infarction, and unstable angina. Results: The difference in mean platelet indices between the 3 study groups was significantly higher in MI and UA groups compared to healthy control. Mean platelet count in the control group was $2.60 \mathrm{Lac}( \pm 0.92)$, cases of MI $2.34 \mathrm{Lac}( \pm 0.67)$, and in cases of unstable angina $2.56 \mathrm{Lac}( \pm 0.89)$. Conclusion: From the present study, it can be conclude that larger platelets can play a significant role in CAD. As platelet volume indices (PVI) can provide an alarming sign for the prethrombotic state in IHD. So in day to day routine hematological analysis of PVI and large platelets can help in the management of coronary artery disease.

Keywords: Coronary artery disease, Platelet, Platelet volume indices, Hematological analysis

Corresponding Author

Gunvanti Rathod, Associate Professor, Department of Pathology, GMERS Medical College, Ahmedabad, Gujarat, India.

Email: neempath@gmail.com
How to Cite this Article

Gamit M, Rathod G. Correlation of platelet count and platelet volume indices with coronary artery diseases. Trop J Pathol Microbiol. 2020;6(4):309312.

\section{Available From}

https://pathology.medresearch.in/index.php/jopm/ar ticle/view/458
To Browse

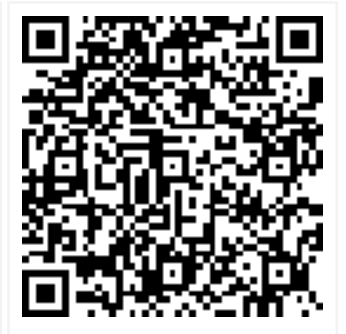

\section{Introduction}

Coronary artery disease is the most common non-communicable disease in the world. The WHO has drawn attention to the fact that CAD is a modern epidemic more in the geriatric population i.e. people above 60 years of age.

Manuscript Received 08-04-2020

Conflict of Interest No

Review Round 1
$19-04-2020$
Funding
Nil

$$
\begin{gathered}
\text { Review Round } 2 \\
\text { 24-04-2020 }
\end{gathered}
$$

(c) 2020 by Mital Gamit, Gunvanti Rathod and Published by Siddharth Health Research and Social Welfare Society. This is an Open Access article licensed under a Creative Commons Attribution 4.0 International License https://creativecommons.org/licenses/by/4.0/ unported [CC BY 4.0].

A large increase in CAD is projected and now it is the most common cause of death. Platelets play a crucial role in the pathogenesis of atherosclerotic complications, contributing to thrombus formation or apposition after plaque rupture $[1,2,3]$. After rupture of arteriosclerotic plaque in coronary

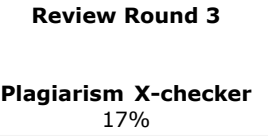

Review Round 3 Plagiarism X-checker $17 \%$

Accepted 28-04-2020

Note 
Arteries, platelet hyperactivity and local platelet activation have been suggested to play a causal role in prothrombotic events leading to MI13. Increased platelet reactivity and shortened bleeding time are associated with increased platelet volume, therefore; platelet size has been considered to reflect platelet level of activity as the large platelets are more active than small platelets and they have a higher thrombotic potential due to high concentration of thromboxane $\mathrm{A} 2$. So divergence in the platelet indices is a good indicator for the identification and management of CVD. The aim of this study was to study platelet parameters in the spectrum of ischemic artery disease and to attempt a clinicopathological correlation.

\section{Materials and Methods}

This prospective study was done in the hematological section of the pathology department at tertiary care hospital over a period of two years from January 2016 to December 2018. The current study had taken prior Institutional ethics committee approval for the same study.

Inclusion and exclusion criteria: Inclusion criteria for the study included the patients already diagnosed as acute myocardial infarctions (AMI) and angina by the physicians and healthy volunteers whose age and sex-matched with a normal electrocardiogram. The exclusion criteria included all the other patients of heart disease.

In this study, the population was divided into three groups:

The first group included (30) thirty patients with a diagnosis of acute myocardial infarctions (AMI). The second group included (30) thirty patients diagnosed as having unstable angina. The third group included (30) thirty healthy control groups.

Sample collection: The current study had collected data in the form of a complete blood count from a total of 90 study populations. For that, $2 \mathrm{ml}$ of blood was collected in EDTA and analyzed in the HORIBA 5 part hematological analyzer. The system gave the following hematological parameter: $\mathrm{RBC}$, HGB, HCT, MCV, MCH, MCHC, RDW-CV, RDW-SD, PLT, PDW, PCT, MPV, Differential Percentage of WBCs. etc.

Statistical analysis: Data were translated into a computerized database structure. An expert statistical advice was sought for statistical analyses that were computer-assisted using SPSS version 20
(Statistical Package for Social Sciences). The outcome quantitative variables were normally distributed and conveniently described by mean, SD (standard deviation), and the parametric statistical tests of significance were used. The P-value less than the 0.05 level was considered statistically significant.

\section{Results}

According to Table 1 , a total of 90 subjects were analyzed, 30 healthy controls with a mean age of 46 year $( \pm 4.5)$ and 30 MI cases with a mean age 52.4 $( \pm 6.12)$ and 30 cases with unstable angina with a mean age of $51.5( \pm 4.5)$ and mean age of all cases 51.6 ( \pm 0.94). According to Table 2, males constituted $66.67 \%$ of healthy control, $60.33 \%$ of MI, and $76.06 \%$ of cases with unstable angina. No important differences were observed between 3 study groups. Females constituted $33.33 \%$ of healthy control, $39.67 \%$ of MI, and $23.94 \%$ of cases with unstable angina. No important differences were observed between 3 study groups. Males had a higher incidence of MI and UA than females. The difference in mean platelet indices between the 3 study groups was as per Table 3 which was significantly higher in MI and UA groups compared to healthy control. Mean platelet count in the control group was $2.60 \mathrm{Lac}$ ( \pm 0.92 ), cases of MI 2.34 Lac $( \pm 0.67)$, and in cases of unstable angina 2.56 Lac $( \pm 0.89)$. Platelet count was higher in the control group than in other groups. Mean platelet distribution width in the control group was 10.25 $( \pm 2.03)$, in cases of MI $18.32( \pm 2.98)$ and in cases of unstable angina $17.23 \quad( \pm 3.02)$. Platelet distribution width was significantly higher in cases of MI and unstable angina than the control group. Mean platelet volume in the control group was 8.07 $( \pm 2.11)$, in cases of MI $12.3( \pm 1.98)$ and in cases of unstable angina $11.6( \pm 2.01)$. Platelet volume was significantly higher in cases of MI and unstable angina then control group. Mean platelet concentrate in the control group was $0.23( \pm 0.04)$, in cases of MI $0.29( \pm 0.11)$ and in cases of unstable angina $0.32( \pm 0.12)$. Mean platelet concentrate was significantly higher in cases of MI and unstable angina than the control group.

Table-1: Age-wise distribution of cases

\begin{tabular}{|l|l|}
\hline \multicolumn{1}{|c|}{ Cases } & \multicolumn{1}{|c|}{ Age (Mean \pm SD) } \\
\hline MI (30) & $52.40 \pm 6.12$ \\
\hline UA (30) & $51.5 \pm 4.50$ \\
\hline Control (30) & $46.80 \pm 4.51$ \\
\hline Total (90) & $51.92 \pm 0.89$ \\
\hline
\end{tabular}


MI - Mycardial infarction

UA - Unstable angina

Table-2: Sex wise distribution of cases.

\begin{tabular}{|l|l|l|}
\hline \multicolumn{1}{|c|}{ Cases } & \multicolumn{1}{c|}{ Sex } & \multicolumn{1}{c|}{ No. (\%) } \\
\hline \multirow{2}{*}{ MI } & Male & $19(60.33 \%)$ \\
\cline { 2 - 3 } & Female & $11(39.67 \%)$ \\
\hline \multirow{3}{*}{ UA } & Male & $23(76.06 \%)$ \\
\cline { 2 - 3 } & Female & $07(23.94 \%)$ \\
\hline \multirow{2}{*}{ Control } & Male & $20(66.67 \%)$ \\
\cline { 2 - 3 } & Female & $10(33.33 \%)$ \\
\hline Total & & 90 \\
\hline
\end{tabular}

Table-3: Comparison of platelet count and platelet indices in all cases

\begin{tabular}{|c|c|c|c|c|}
\hline Cases & $\begin{array}{c}\text { Platelet } \\
\text { count } \\
\text { (Mean } \pm \text { SD) }\end{array}$ & $\begin{array}{l}\text { Mean platelet } \\
\text { volume(Mean } \pm \\
\text { SD) }\end{array}$ & $\begin{array}{c}\text { Platelet } \\
\text { distribution } \\
\text { width(Mean士 SD) }\end{array}$ & $\begin{array}{l}\text { PCT(Me } \\
\text { ant SD) }\end{array}$ \\
\hline MI & $2.34 \pm 0.67$ & $12.3 \pm 1.98$ & $18.32 \pm 2.98$ & $\begin{array}{l}0.29 \\
\pm 0.11\end{array}$ \\
\hline UA & $2.56 \pm 0.89$ & $11.6 \pm 2.01$ & $17.23 \pm 3.02$ & $\begin{array}{l}0.32 \\
\pm 0.12\end{array}$ \\
\hline Control & $2.60 \pm 0.92$ & $8.07 \pm 2.11$ & $10.25 \pm 2.03$ & $\begin{array}{l}0.23 \\
\pm 0.04\end{array}$ \\
\hline Total & $2.34 \pm 0.78$ & $10.3 \pm 2.43$ & $15.01 \pm 3.57$ & $\begin{array}{l}0.28 \\
\pm 0.15\end{array}$ \\
\hline$p$ & NS & $P<0.05$ & $P<0.05$ & $P<0.05$ \\
\hline
\end{tabular}

\section{Discussion}

Platelets have been implicated in the pathogenesis of cardiovascular disorders, including atherosclerosis and its complications, such as acute myocardial infarction (AMI), unstable angina (UA), and sudden cardiac death. Platelet hyperreactivity and local platelet activation have been suggested to play a causal role in acute coronary events [4]. Platelet size has been shown to reflect platelet activity. Large platelets are metabolically and enzymatically more active than small platelets and produce more thromboxane A2 [5,6]. Generalized platelet activation occurs before an acute coronary event. The increase in platelet consumption at the site of the coronary atherosclerotic plaque causes larger platelets to be released from the bone marrow. The truth that the increase persists even after discharge from the hospital supports the view that platelet volume is chronically larger in the infarct group [7]. This suggests that PVI, particularly MPV, are indicators of the degree of damage already done and that these markers maintain their strength and predictive value for a long time. In the present study, MPV and mean PDW were significantly higher
In AMI/UA patients than stable angina, and statistically significantly higher PDW and MPV were also observed in AMI/UA patients than controls. Our results are similar to that of Khandekar, et al. [8], who also showed higher MPV and mean PDW in AMI or UA patients than stable CAD. Martin, et al. [9] found that MPV was significantly higher in those patients who have MI, compared with the healthy group, which is confirmed by Senaran, et al. [10], both studies are similar to the present study that MPV was significantly higher in patients of MI. Mathur et al. [11] found platelet counts to be significantly lower and MPV to be higher in patients with unstable angina pectoris and MI. Different from the present study, the platelet count is increased significantly in MI and UA. MPV, in the present study, is higher in both MI and UA which is similar to Mathur, et al. [11] study. Another study by Khode [12], found the mean platelet volume was significantly higher in patients with AMI $(9.65 \pm$ $0.96)$ as compared to controls $(9.21 \pm 0.58)$. A study by Jasani, et al. [13], and Senaran, et al. [10], both studies are similar to the present study that MPV was significantly higher in patients of MI. After a comparison of the current study to the all above studies showed that platelet indices were deranged in the patients of MI as well as angina in comparison to the healthy controls.

\section{Limitation of the study}

In the present study the study population is small that is the main limitation.

\section{Conclusion}

From the present study, it can be concluded that larger platelets can play a significant role in CAD. As platelet volume indices (PVI) can provide an alarming sign for the prethrombotic state in IHD. So, in day to day routine hematological analysis of PVI and large platelets can help in the management of coronary artery disease.

\section{What does this study add to existing knowledge?}

In routine day to day practice, specifically, platelet volume indices are ignored by pathologists as well as clinicians. After observing the present study, it can be observed that platelet count and platelet volume indices can provide a signature for the prethrombotic state in ischemic heart disease. Measurement of platelet count and platelet volume 
Indices may be of some benefit in detecting those patients at higher risk of the acute coronary syndrome.

\section{Author's contribution}

Both authors, Dr. Mital Gamit and Dr. Gunvanti

Rathod had equally and actively involved in the study process, conduct, and manuscript preparation.

\section{Reference}

01. Boos CJ, Lip GY. Platelet activation and cardiovascular Outcomes in acute coronary syndromes. J Thromb Haemost. 2006;4(12)2542-2543.

doi:[Article:https://doi.org/10.1111/j.1538-7836.

2006.02250.x][Crossref]

02. Tsiara S, Elisaf M, Jagroop IA, Mikhailidis DP. Platelets as predictors of vascular risk- is there a practical index of platelet Activity. Clin Appl Thromb Hemost. 2003; 9;177-190.

doi:

[Article:https://doi.org/10.1177/1076029603009003 01][Crossref]

03. Mathur A, Robinson MS, Cotton J, Martin JF, Erusalimsky JD. Platelet reactivity in acute coronary syndromes- evidence for differences in platelet behaviour between unstable angina and myocardial infarction. Thromb Haemost. 2001;85(6)989-994.

[Crossref differences in platelet behaviour between unstable angina and myocardial infarction]

04. Khandekar MM, Khurana AS, Deshmukh SD, Karani $A L$, Katdare AD, Inamdar AK. Platelet volume indicies in patient with coronary artery disease and acute myocardial infarction- An Indian scenario. J Clin Path. 2006;59(2)146149 .

doi:

[Article:https://doi.org/10.1136/jcp.2004.025387]

[Crossref]

05. Khode V, Sindhur J, Kanbur D, Ruikar K, Nallulwar S. Mean platelet volume and other platelet volume indices in patients with stable coronary artery disease and acute myocardial infarction- A case control study. J Cardiovasc Dis Res. 2012; 3(4)272-275.

doi: [Article:https://doi.org/10.4103/09753583.102694][Crossref]
06. Trip MD, Cats VK, van Capelle FJL, Vreeken J. Platelet hyper reactivity and prognosis in survivors of myocardial infarction. New Engl J Med. 1990;322(22)1549-1554.

doi:

[Article:https://doi.org/10.1056/NE]M199005313222 201][Crossref]

07. Corash L, Tan H, Grolnick HR. Heterogeneity of human whole blood platelet subpopulations I Relationship between buoyant density, cell volume and ultrastructure. Blood. $1977 ; 49(1) 71-87$.

[Crossref]

08. Thompson CB, Eaton KA, Princiotta SM, et al. Size-dependent platelet subpopulationrelationship of platelet volume to ultrastructure, enzymatic activity and function. $\mathrm{Br} \mathrm{J}$ Haematol. $1982 ; 50(3) 509-520$.

doi: [Article:https://doi.org/10.1111/j.13652141.1982.tb01947.x][Crossref]

09. Cameron EA, Phillips R, Ibbatson RM, Carson $\mathrm{PH}$. Platelet size in myocardial infarction. BMJ. $1983 ; 287 ; 449-451$.

doi:[Article:https://doi.org/10.1136/bmj.287. 6390.449][Crossref]

10. Martin J F, Bath P M, Burr M L. Influence of platelet size on outcome after myocardial infarction. Lancet. 1991;388(8780)1403-1411.

doi: [Article:https://doi.org/10.1016/01406736(91)92719-i][Crossref]

11. Senaran H, Ileri M, Altinbas A, A Koşar, E Yetkin, $M$ Oztürk, et al. Thromboietin and mean platelet volume in coronary artery Disease. Clini Cardiol. $2001 ; 24(5) 405-408$.

doi:

[Article:https://doi.org/10.1002/clc.4960240511] [Crossref]

12. Jasani J, Modi M. Evaluation of platelet count and platelet indices in patients with coronary artery disease. IJBAR. 2014;5(11)553-555. doi: [Article:https://doi.org/10.7439/ijbar.v5i11.978] [Crossref]

13. Jesty J, Yin W, Perrotta P, Bluestein D. Platelet activation in a circulating flow loop- combined effects of shear stress and exposure time. Platelets. 2003;14(3)143-149.

doi:

[Article:https://doi.org/10.1080/0953710031000092 839][Crossref] 